\title{
Comparative Study Between Endoscopic Thyroid Surgery via the Oral Vestibular Approach and the Areola Approach
}

\author{
Fangdong Guo, MS, ${ }^{1}$ Wenrui Wang, $M{ }^{2},{ }^{2}$ Xiaoyu Zhu, MS, ${ }^{1}$ Cheng Xiang, MD, ${ }^{3}$ \\ Ping Wang, $\mathrm{MD}^{3}$ and Yong Wang, $\mathrm{MD}^{3}$
}

\begin{abstract}
Objective: To investigate the clinical efficacy and safety of endoscopic thyroidectomy through the oral vestibular approach and the breast approach.

Methods: Retrospective analysis was done on clinical data of 80 patients who received an endoscopic thyroidectomy from April 2018 to March 2019. The research group had endoscopic thyroidectomy through the oral vestibular approach, whereas the control group had endoscopic thyroidectomy through the areola breast approach. Comparison between the two groups including intraoperative bleeding, operation time, total postoperative drainage, drainage time, postoperative sustained pain time, recovery feeding time, postoperative hospitalization duration, satisfactory esthetic outcomes of incision, central lymph node clearance, skin injury, infection incidence, and complications such as facial hematoma, subcutaneous emphysema, abnormal feeling of the neck and chest, and pleural injury was recorded.

Results: There was no significant difference between the two groups in the amount of intraoperative bleeding, operation time, total postoperative drainage, drainage time, postoperative sustained pain time, recovery feeding time, and postoperative hospitalization time $(P>.05)$. The incidence of complications such as skin injury, infection, wound hematoma, subcutaneous emphysema, abnormal feeling of the neck and chest, and pleural injury was not statistically different between the two groups $(P>.05)$. There was no significant difference in the number of lymph nodes cleaned in the central area between the two groups $(P>.05)$. The overall satisfaction of the patients with the cosmetic effects of the incision $(100.00 \%)$ was higher than that of the control group $(90.00 \%)$.

Conclusions: The clinical treatment effect and safety in the two groups were similar, but the transoral group had better cosmetic effects.
\end{abstract}

Keywords: endoscopic thyroidectomy, areola breast approach, transoral vestibular approach, thyroid cancer

\section{Introduction}

$\mathbf{E}$ NDOSCOPIC THYROIDECTOMY through the breast approach has a good clinical effect, and rather than the neck incision, relatively less visible part of the body is incised, leading to more satisfactory cosmetic outcomes. ${ }^{1}$ With the improvement of endoscopy instruments and the concept of minimally invasive cosmetic thyroid surgery, endoscopic thyroid surgery has been rapidly and widely performed worldwide because of the concealed incision, small trauma, and good cosmetic results. ${ }^{2}$ The search for surgical techniques that are low trauma, small scar, and even scar free has become the challenge for thyroid surgeons. The chest-breast approach has been performed for nearly two decades. ${ }^{3,4}$ However, some women were resistant to even small incisions on the anterior chest. Also, for the reason of sternal and clavicular obstruction, cleaning the lower central compartment lymph nodes is more difficult with the breast approach. As a result, natural orifice transluminal endoscopic surgery (NOTES) approaches through the oral cavity may be the primary solution for advanced scarless thyroid surgery. ${ }^{5}$ At present, translumenal endoscopic interventions through natural orifices are gaining increasing interest because they allow surgical treatment without any incision of the skin.

${ }^{1}$ Department of Breast and Thyroid Surgery, The Affiliated Zhongshan Hospital of Dalian University, Dalian, China.

${ }^{2}$ Department of Breast and Thyroid Surgery, Dezhou People's Hospital of Shandong Province, Dezhou, China.

${ }^{3}$ Department of Thyroid Surgery, The Second Affiliated Hospital of Zhejiang University College of Medicine, Hangzhou, China. 
Table 1. Patient Clinical Characteristics

\begin{tabular}{lcccc}
\hline & $\begin{array}{c}\text { Study } \\
\text { group }(40)\end{array}$ & Control (40) & $\mathrm{t}$ & $\mathrm{P}$ \\
\hline Age & $29.8 \pm 0.96$ & $33.75 \pm 1.19$ & -2.587 & $>.05$ \\
Height $(\mathrm{cm})$ & $159.73 \pm 2.49$ & $162.45 \pm 0.78$ & -1.048 & $>.05$ \\
Weight $(\mathrm{kg})$ & $57.66 \pm 2.97$ & $58.98 \pm 1.93$ & -0.369 & $>.05$ \\
Diameter $(\mathrm{cm})$ & $0.608 \pm 0.034$ & $0.582 \pm 0.034$ & 0.512 & $>.05$ \\
\hline
\end{tabular}

The innovative practice of thyroid surgery in the field of thyroid surgery through transoral endoscopy thyroidectomy via the vestibular approach (TOETVA) is the latest exploration of minimally invasive thyroidectomy. Until now, the transoral approach was reported to effectively treat thyroid cancer and benign tumors. ${ }^{6-8}$ The difference between TOETVA and chest approach endoscopic thyroid treatment has not been reported to date. In our article, we aim to analyze the treatment of patients undergoing either the areola breast approach or the transoral vestibular approach to explore the clinical efficacy and safety of the two approaches.

\section{Methods}

\section{Clinical data and methods}

Inclusion/exclusion criteria. We selected 80 patients who underwent laparoscopic thyroid surgery at the department of thyroid surgery of the Second Affiliated Hospital, Zhejiang University College of Medicine, from April 2018 to March 2019 as subjects, including 40 patients who underwent the areola breast approach and 40 patients who underwent transoral vestibular approach thyroidectomy. All the patients are women, with an average age of $31.8 \pm 7.0$ years. The patients received ultrasound and cervical computed tomographic enhancement scans before surgery, after which the patients with suspected tumors underwent thyroid fine-needle aspiration cytology before surgery. All the patients included were diagnosed with thyroid papillary carcinoma postoperatively. There was no significant difference in the general clinical characteristics between the two groups $(P>.05)$.

The inclusion criteria were as follows: (1) women without a history of neck surgery; (2) normal thyroid and parathyroid function; (3) papillary thyroid microcarcinoma (PTMC) (tumor diameter $\leq 1 \mathrm{~cm}$ ); (4) no capsular invasion; (5) no cervical lateral lymph node metastasis; and (6) normal blood analysis, coagulation, chest radiograph, laryngoscopic vocal cord function, and biochemical function as tested preoperatively.
Surgical procedure. Areola breast approach group: the endoscopic thyroidectomy through the anterior chest and breast approach for PTMC surgery is based on our experience, as described previously. ${ }^{4}$ In brief, after general anesthesia with endotracheal intubation, the surgeon marks the tumor location, thyroid cartilage, sternal angle, sterno-lock joint, and lateral margin of the sternocleidomastoid muscle in the patient's neck. Expansion fluid (1:500,000 adrenaline saline $70 \mathrm{~mL}+20 \mathrm{~mL}$ ropivacaine) is injected into the observation tunnel to create a space for surgery. According to the "seven-step" method, we resect the thyroid gland endoscopically through the areola approach, as follows: (1) expose the thyroid gland, (2) expose the trachea, (3) expose the common carotid artery, (4) disconnect the upper thyroid blood vessel, (5) break the thyroid lower blood vessel, (6) expose the recurrent laryngeal nerve (RLN) and functional protection, and (7) retain the upper parathyroid gland in situ, and completely remove thyroid gland.

TOETVA: with the patient in the supine position and using a neurological monitoring catheter, general anesthesia is given through an orotracheal intubation. The orotracheal intubation should be fixed in the left side of the mouth without the use of a dental pad. ${ }^{9,10}$ The steps are as follows: (1) a 10-mm transverse incision or "ridge type" incision is made above the median and lower lip ligament of the oral vestibule; (2) an electrosurgical scalpel is used to separate the orbicularis along the periosteal surface to the lower edge of the mandible; (3) an inflation fluid is injected under the anterior neck (1:500,000 epinephrine in saline $40 \mathrm{~mL}+10 \mathrm{~mL}$ ropivacaine); and (4) the cavity is built and a $10-\mathrm{mm}$ trocar is inserted for observation. It is important to protect the corners of the mouth to prevent the incision mucosa from friction. In general, the thyroidectomy procedure is similar to the areola breast approach in our center; in addition, the central area lymphadenectomy is performed consistent with an open surgery procedure.

Therapeutic effect and cosmetic results evaluation. Intraoperative bleeding, operation time, total postoperative drainage, drainage time, postoperative sustained pain duration, recovery feeding, and postoperative hospitalization time were compared between the two groups. The complications such as skin injury, infection, wound hematoma, subcutaneous emphysema, neck and chest abnormal feeling, and pleural injury were recorded.

The cosmetic satisfaction data were collected as follows: the score was measured 1 month after surgery by visual analog scale. A vernier caliper, $\sim 10 \mathrm{~cm}$ in length, is marked with 10 divisions, and the 2 ends of the caliper represent " 0. ." Within the 10 divisions, 0 points means the esthetic effect is

Table 2. Patient Postoperative Characteristics

\begin{tabular}{lcccccccc}
\hline & & $\begin{array}{c}\text { Intraoperative } \\
\text { Group }\end{array}$ & $\begin{array}{c}\text { Numberation } \\
\text { time } \\
\text { bleeding }(m L)\end{array}$ & $\begin{array}{c}\text { Postoperative } \\
\text { (minutes) }\end{array}$ & $\begin{array}{c}\text { Drainage }(m L) \\
\text { drainase }\end{array}$ & $\begin{array}{c}\text { Postoperative } \\
\text { pain time } \\
\text { (days) }\end{array}$ & $\begin{array}{c}\text { Feeding } \\
\text { time } \\
\text { (minutes) }\end{array}$ & $\begin{array}{c}\text { Hospitalization } \\
(\text { days })\end{array}$ \\
\hline $\begin{array}{l}\text { Study } \\
\text { group }\end{array}$ & 40 & $14.49 \pm 7.54$ & $171.98 \pm 5.34$ & $179.00 \pm 7.78$ & $4.25 \pm 0.10$ & $1.21 \pm 0.52$ & $442.53 \pm 6.96$ & $4.33 \pm 0.08$ \\
$\begin{array}{c}\text { Control } \\
\text { group }\end{array}$ & 40 & $15.87 \pm 6.21$ & $162.63 \pm 5.02$ & $171.63 \pm 6.84$ & $4.15 \pm 0.11$ & $1.26 \pm 0.48$ & $444.35 \pm 8.88$ & $4.18 \pm 0.11$ \\
$t$ & & 2.097 & 1.248 & 0.683 & 0.653 & 0.746 & -0.159 & 1.038 \\
$P$ & $>.05$ & $>.05$ & $>.05$ & $>.05$ & $>.05$ & $>.05$ & $>.05$ \\
\hline
\end{tabular}


Table 3. Postoperative Complications

\begin{tabular}{|c|c|c|c|c|c|c|}
\hline Group & Number & Succus fluid (\%) & Skin injury (\%) & Infection (\%) & $\begin{array}{c}\text { Cervical and } \\
\text { chest dysplasia }(\%)\end{array}$ & $\begin{array}{c}\text { Pleural } \\
\text { injury (\%) }\end{array}$ \\
\hline Study group & 40 & $2(5.00)$ & $1(2.50)$ & $1(2.50)$ & $3(7.50)$ & $1(2.50)$ \\
\hline Control group & 40 & $2(5.00)$ & $5(12.5)$ & $0(0.00)$ & $2(5.00)$ & $0(0.00)$ \\
\hline$\chi^{2}$ & & 0.00 & 2.883 & 1.01 & 0.21 & 1.01 \\
\hline$P$ & & $>.05$ & $>.05$ & $>.05$ & $>.05$ & $>.05$ \\
\hline
\end{tabular}

very poor and the patient is dissatisfied; 10 points means the patient is very satisfied. The clinical evaluation divisions were as follows: 0 to 3 means fair cosmetic effects, 4 to 6 means moderate cosmetic effects, and 7 to 10 means good cosmetic effects.

Finally, the lymph node dissection of central area was compared between the two groups.

Statistical processing. The data were analyzed using SPSS 20.0 statistical software. The measured data were expressed as $x \pm s$, and the $t$-test was used for two-sample comparison. The count data were analyzed by the chi-square test, and the difference was statistically significant at $P<.05$.

\section{Results}

\section{Comparison of clinical data}

We retrospectively chose 40 patients who had undergone the transoral approach and 40 patients who had undergone the breast approach for thyroidectomy. There were no significant differences in age, height, weight, and maximum tumor diameter between the two groups $(P>.05)$ (Table 1), which excludes the clinical data deviation between the two groups.

\section{Surgical outcomes comparison}

During the hospital stay, surgically related data were recorded to evaluate the recovery after transoral and breast approach surgeries. There were no significant differences in the intraoperative bleeding, operation time, total postoperative drainage, drainage time, postoperative sustained pain time, recovery feeding time, postoperative hospitalization time, and hospitalization expenses between the two groups $(P>.05)$ (Table 2).

\section{Complications comparison}

To evaluate the surgical complications in each group, the primary endoscopy thyroid surgery-related outcomes were compared. There were no significant differences in the incidence of complications such as subcutaneous fluid, skin

Table 4. Comparison of Cosmetic EfFects

\begin{tabular}{lccccc}
\hline Group & Number & Fair & Medium & Good & $\begin{array}{c}\text { Cosmetic } \\
\text { effect score }\end{array}$ \\
\hline Study group & 40 & 1 & 4 & 35 & $8.59 \pm 1.59$ \\
The control & 40 & 4 & 25 & 11 & $5.56 \pm 1.83$ \\
$\quad$ group & & & & & 8.023 \\
$t$ & & & & & $<.05$ \\
$P$ & & & & \\
\hline
\end{tabular}

injury, infection, cervical and chest dysplasia, and pleural injury between the two groups $(P>.05)$ (Table 3$)$.

\section{Cosmetic effects comparison}

We carried out the cosmetic effects follow-up 1 month after the operation. Patients were asked to complete the cosmetic scale according to their satisfaction with the esthetic result. The cosmetic score of the incision in the study group $(8.59 \pm 1.59)$ was significantly higher than that in the transoral group (5.56 \pm 1.83$)$, and the difference was statistically significant $(P<.05)$ (Table 4 and Fig. 1A, B).

\section{Central lymph node dissection comparison}

Central lymph node dissection is one of the primary steps during thyroid cancer treatment. According to the pathological results of the central lymph nodes in the two groups, the number of untransferred lymph nodes was $6.43 \pm 0.65$ and $6.73 \pm 0.70$ in the transoral group and the breast approach group, respectively, and the number of transferred lymph nodes was $1.00 \pm 0.27$ and $0.80 \pm 0.19$, respectively. The difference was not statistically significant $(P>.05)$ (Table 5).

\section{Discussion}

The neck skin area is the area routinely affected by traditional thyroid surgery, and a 4 to $6 \mathrm{~cm}$ scar will be left on the neck. If the particular patient has scar diathesis, the patient's confidence will be affected. Therefore, thyroid surgeons have been looking for another place on the body where the incision would be partly of fully hidden. In 1997, Hascher first reported on endoscopic thyroidectomy, which achieved a satisfactory esthetic result and laid the foundation for the development of endoscopic thyroidectomy. ${ }^{11}$ After $>20$ years of development, indications for endoscopic thyroidectomy had expanded to differentiated thyroid cancer, especially PTMC.
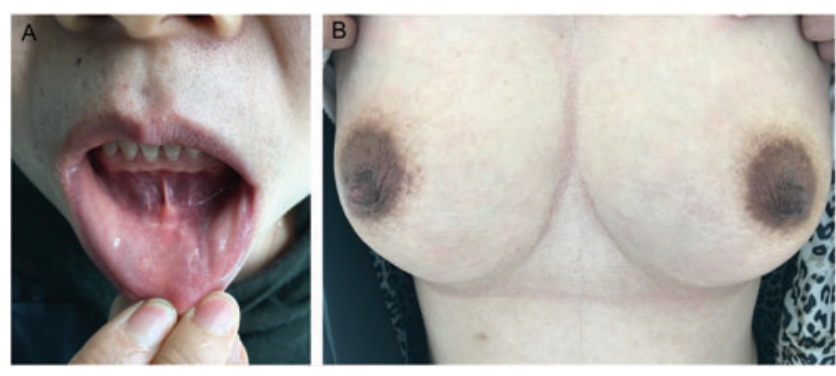

FIG. 1. Incision in TOETVA and areola breast approach. (A) Latent oral scar in TOETVA. (B) Three incisions in areola approach thyroid surgery. TOETVA, transoral endoscopy thyroidectomy via the vestibular approach. 
Table 5. Pathological Results of Central Lymph Nodes Dissection

\begin{tabular}{lccc}
\hline & $\begin{array}{c}\text { Untransferred } \\
\text { lymph } \\
\text { nodes }\end{array}$ & $\begin{array}{c}\text { Transferred } \\
\text { lymph } \\
\text { nodes }\end{array}$ & $\begin{array}{c}\text { Total } \\
\text { lymph } \\
\text { nodes }\end{array}$ \\
\hline $\begin{array}{cccc}\text { Study } \\
\text { group }\end{array}$ & $6.43 \pm 0.65$ & $1.00 \pm 0.27$ & $7.43 \pm 0.68$ \\
$\begin{array}{c}\text { Control } \\
\text { group }\end{array}$ & $6.73 \pm 0.70$ & $0.80 \pm 0.19$ & $7.53 \pm 0.67$ \\
$t \quad$ & -0.308 & 0.616 & -0.102 \\
$P$ & $>.05$ & $>.05$ & $>.05$ \\
\hline
\end{tabular}

In our center, we chose patients to receive endoscopic thyroidectomy based on commonly recognized indications and contraindications ${ }^{12}$ that exclude patients without cosmetic requirements, suspected distant transfer, tumor invasion, and those with secondary surgery.

In this study, clinical outcomes were recorded for two patient groups: the oral vestibular approach group and the breast areola approach group. The results showed that intraoperative blood loss, operative time, total postoperative drainage, drainage time, postoperative persistent pain, resuming eating, postoperative hospitalization, and complications rate including subcutaneous fluid, skin damage, infection, neck and chest dysfunction, pleural injury, and the number of central lymph nodes dissected were not statistically different between the two groups. These results were in accordance with our expectation, which suggest that both methods are safe and effective.

In terms of cosmetic satisfaction with the incision, the results of the study showed that the oral vestibular approach had a better cosmetic effect than the breast areola approach, because the oral approach leaves no scar. However, transoral endoscopic thyroidectomy converts type I incisions into type II incisions, increasing the risk of infection. Only 1 patient in this group had a short-term infection of the neck, which was controlled with antibiotics. At present, we prevent infection by using broad-spectrum antibiotics during the perioperative period and by giving the patients concentrated tinidazole mouthwash before surgery. In addition to these measures, we believe that the most important measure to prevent infection is patent drainage. In this group, 1 case of infection was caused by poor drainage. After drainage tube adjustment, the infection was resolved within 24 hours. One case of pleural injury was due to the discovery of a VII area lymph node that was close to the pleura, resulting in minor damage to the pleura. The patient did not have pneumothorax after surgery and recovered. Although there was no statistically significant difference in the lymph nodes of the central region during the study, the lymph node dissection of the central region is very convenient during transoral endoscopic thyroidectomy because of the angle toward the foot side, especially in dissection of the lower VII area lymph nodes, which can be more thoroughly cleaned. Because the endoscope has good magnification and illumination, lymph node dissection in the VII area through oral thyroid surgery is even more convenient than in open surgery. Therefore, we advise patients to receive TOETVA with early preoperative $\mathrm{cNla}$ thyroid papillary carcinoma, if there is no evidence of lateral lymph node metastasis before surgery.
TOETVA surgery has many advantages. Most importantly, TOETVA is a totally scarless surgery. Not only is TOETVA convenient to cleaning region VI and VII lymph nodes, but also the method allows easy identification and retention of the lower parathyroid. However, TOETVA has some limitations. Patients with a long jaw are not good candidates, and cervical lateral neck lymph dissection is contraindicated. For beginning surgeons, TOETVA can be difficult. Owing to the blockage of thyroid cartilage, the space is narrow, and the angle between the instruments creates a "chopstick effect," increasing the difficulty of prelaryngeal lymph node dissection and superior pole thyroid management. We found, based on our experience, that nerve monitoring during surgery prevents RLN damage. ${ }^{13}$

In contrast, the areola breast approach also has some advantages. First, the procedure is relatively simple. The procedure has been performed for $\sim 20$ years, and it is also widely used in clinical practice with good clinical efficacy. ${ }^{14}$ The risk of infection is greatly reduced because of the type I surgical incision. The operating angle is better for thorough prelaryngeal lymph node cleaning accompanied by superior parathyroid protection. Nevertheless, owing to the obstruction of the sternum and clavicle, it is difficult to clean the lymph nodes in the lower VI and VII regions, and to retain the lower parathyroid gland, especially the type B parathyroid gland.

After many years of clinical exploration, the endoscopic thyroidectomy approach has been diversified, and the clinical choice should be based on the patient's condition and cosmetic requirements. TOETVA, as a new scarless approach for thyroid surgery, is an innovation in the concept of thyroid surgery. Under the premise of ensuring the quality of surgery, TOETVA achieves minimally invasive and beautiful effects, reflecting the treatment concept of NOTES. In the future, TOETVA will remain one of the hotspots in clinical practice and research in the field of endoscopic thyroid surgery. Our preliminary results show that the clinical efficacy and safety of the two groups are basically similar. TOETVA is safe and effective for patients after strict surgical procedure, and has good cosmetic and minimally invasive effects. TOETVA is also effective for patients with early-differentiated thyroid cancer, especially those with little lymph node metastasis in the VI region. In the future, we will conduct prospective research to continuously optimize the operation and further observe the short-term and long-term effects of transoral endoscopic thyroidectomy.

\section{Disclosure Statement}

No competing financial interests exist.

\section{Funding Information}

This study was supported by Zhejiang Provincial Basic Public Welfare Project (Grant No. LGF18H160002).

\section{References}

1. Vidal O, Saavedra-Perez D, Vilaca J, Pantoja JP, DelgadoOliver E, Lopez-Boado MA, et al. Minimally-invasive endocrine neck surgery. Cir Esp 2019;97:305-313.

2. Cao F, Xie B, Cui B, Xu D. Endoscopic vs. conventional thyroidectomy for the treatment of benign thyroid tumors: 
A retrospective study of a 4-year experience. Exp Ther Med 2011;2:661-666.

3. Guo Y, Qu R, Huo J, Wang C, Hu X, Chen C, et al. Technique for endoscopic thyroidectomy with selective lateral neck dissection via a chest-breast approach. Surg Endosc 2019;33:1334-1341.

4. Wang $\mathrm{P}, \mathrm{Li} \mathrm{ZY}, \mathrm{Xu}$ SM. [Endoscopic thyroidectomy through anterior chest and breast approach for papillary thyroid microcarcinoma]. Zhonghua Wai Ke Za Zhi [Chinese journal of surgery] 2008;46:1480-1482.

5. Tartaglia F, Maturo A, Di Matteo FM, De Anna L, Karpathiotakis M, Pelle F, et al. Transoral video assisted thyroidectomy: A systematic review. G Chir 2018;39:276-283.

6. Ahn JH, Yi JW. Transoral endoscopic thyroidectomy for thyroid carcinoma: Outcomes and surgical completeness in 150 single-surgeon cases. Surg Endosc 2019, [Epub ahead of print]; DOI: 10.1007/s00464-019-06841-8.

7. Russell JO, Razavi CR, Shaear M, Chen LW, Lee AH, Ranganath R, et al. Transoral vestibular thyroidectomy: Current state of affairs and considerations for the future. J Clin Endocrinol Metab 2019. pii: jc.2019-00116.

8. Jongekkasit I, Jitpratoom P, Sasanakietkul T, Anuwong A. Transoral endoscopic thyroidectomy for thyroid cancer. Endocrinol Metab Clin North Am 2019;48:165-180.

9. Nakajo A, Arima H, Hirata M, Mizoguchi T, Kijima Y, Mori S, et al. Trans-Oral Video-Assisted Neck Surgery (TOVANS). A new transoral technique of endoscopic thyroidectomy with gasless premandible approach. Surg Endosc 2013;27:1105-1110.
10. Park JO, Sun DI. Transoral endoscopic thyroidectomy: Our initial experience using a new endoscopic technique. Surg Endosc 2017;31:5436-5443.

11. Huscher CS, Chiodini S, Napolitano C, Recher A. Endoscopic right thyroid lobectomy. Surg Endosc 1997;11:877.

12. Chai YJ, Chung JK, Anuwong A, Dionigi G, Kim HY, Hwang KT, et al. Transoral endoscopic thyroidectomy for papillary thyroid microcarcinoma: Initial experience of a single surgeon. Ann Surg Treat Res 2017;93:70-75.

13. Wang Y, Yu X, Wang P, Miao C, Xie Q, Yan H, et al. Implementation of intraoperative neuromonitoring for transoral endoscopic thyroid surgery: A preliminary report. J Laparoendosc Adv Surg Tech A 2016;26:965-971.

14. Wang C, Feng Z, Li J, Yang W, Zhai H, Choi N, et al. Endoscopic thyroidectomy via areola approach: Summary of 1,250 cases in a single institution. Surg Endosc 2015;29: 192-201.

Address correspondence to:

Yong Wang, MD

Department of Thyroid Surgery

The Second Affiliated Hospital of Zhejiang University

College of Medicine

Hangzhou 310009

China

E-mail: surgwy@zju.edu.cn 